slavia, and the Soviet Union between 1945 and 1964 were to be included. The bibliography was not to be arranged by countries, but by periods (1789-1815, 1816-47, 1848-49, 1849$66,1867-1914$, and 1914-1918) and by subject matter: (1) sources and bibliographies; (2) economic history; (3) social and political history and the history of institutions; and (4) the history of arts, sciences, etc.

The work of collecting and arranging the entries was finished during the summer of 1965. The manuscript now contains more than 6,000 titles, giving the bibliographical details about the book, article, or review essay in the original language and in German translation. Where the title gives no clear indication of the content of the work, the editors have added a short annotation. At the end of the entire work there is to be an index to help the reader in using the bibliography. The editorial board, which is composed of experts from all participating countries, dealt with the final problems involved in editing the work when it met in Bucharest in the fall of 1963. Plans are being made to have the bibliography published towards the end of 1966.

Historical Institute PÉTER HANÁK

of the Hungarian Academy of Sciences

Professor Gy. Ránki, assistant director of the Institute for Historical Research of the Hungarian Academy of Sciences, will be in the United States on a Ford Foundation grant from February to July, 1966. Professor Ránki is doing research on nineteenth century economic history.

\title{
NEWS FROM GREAT BRITAIN
}

Carlile A. Macartney, of Oxford University, the well known historian of the Danubian area and particularly of Hungary, celebrated his seventieth birthday on January 24, 1965.

\section{NEWS FROM THE UNITED STATES}

\section{THE AUSTRIAN INSTITUTE}

During the past year and a half most of the activities of the Austrian Institute have been concentrated on fine arts 